\title{
PÉRDIDA DE UNA CHANCE. SU INDEMNIZACIÓN EN LA JURISPRUDENCIA CHILENA
}

\author{
LOSS OF A CHANCE. \\ ITS COMPENSATION IN CHILEAN JURISPRUDENCE \\ PERTE D'Une CHANCE: \\ VOTRE RÉMUNÉRATION DANS LA JURISPRUDENCE CHILIENNE
}

Mauricio Tapia Rodríguez*

\section{INTRODUCCIÓN}

Existen casos de responsabilidad civil en que se desconoce si la negligencia causó efectivamente el daño, pero sí se sabe que al menos destruyó una oportunidad de evitarlo. A este daño se le denomina en el derecho comparado pérdida de una oportunidad o de una chance (el vocablo "chance" es un galicismo aceptado por el Diccionario de la Real Academia Española $)^{1}$.

Por ejemplo, el abogado que omite presentar un recurso y hace perder al cliente la chance de ganar el juicio; el notario que olvida certificar un documento, haciendo perder al cliente una oportunidad de negocio; el transportista que lesiona al caballo antes de la carrera, haciendo perder a su propietario la posibilidad de acceder al premio; el accidente que impide a un estudiante rendir un examen y titularse; el acto de competencia desleal (como una publicidad comparativa engañosa) que impide a un competidor aumentar su clientela; el médico que omite un examen, privando al paciente de la oportunidad de someterse a un tratamiento, o cuando sin ajustarse a la lex artis no se sana una herida, perdiendo el paciente las chances de evitar una invalidez; el retraso del vuelo de un avión, que hace perder al cliente la posibilidad de cerrar un negocio; etcétera.

En todas estas hipótesis existe para la víctima un bien aleatorio que se encontraba en juego (ganar el proceso, cerrar el negocio, recobrar la salud, evitar la muerte, obtener un premio, acceder a una profesión, etcétera) y el agente destruyó

\footnotetext{
* Abogado. Licenciado en Ciencias Jurídicas y Sociales de la Universidad de Chile. Máster en Derecho Privado y Doctor (C) en Derecho Universidad Paris-Est Créteil Val de Marne, Francia. Profesor de Derecho Civil y Director del Departamento de Derecho Privado, Facultad de Derecho, Universidad de Chile.

${ }^{1}$ Sobre la evolución de la pérdida de una oportunidad en Francia (de donde proviene el desarrollo de esta teoría), los estudios de CHABAS, François (1991) "La perte d'une chance en droit français". Coloquio sobre los Développements récents du droit de la responsabilité civile, Ginebra, Centre d'études européennes, pp. 131 y ss.; CHABAS, François (1996). "La perte d'une chance dans le droit français de la responsabilité civile". Responsabilità civile e previdenza, 2, pp. 221 y ss.; y, CHABAS, François (2009). Cien años de responsabilidad civil en Francia [Cent ans de responsabilité civile]. Tapia Rodríguez, Mauricio (Trad.), Santiago: Flandés Indiano, 1a Edición, Edición francesa París: van Dieren Editeur, 2004.
} 
ese potencial de oportunidades con su acción u omisión negligente (olvidó apelar, descuidó certificar un documento, omitió un examen médico, accidentó al caballo, lesionó al postulante, etcétera).

Se estima que es un bien aleatorio -y esto es relevante para discernir su régimen jurídico- porque de todas formas, aun sin haber cometido el agente negligencia alguna, la víctima podría no haber obtenido el beneficio o evitado el perjuicio (se pudo haber rechazado la demanda por otras causas; el negocio se pudo frustrar por desistimiento de la contraparte; el paciente pudo haber de todas formas perecido; el postulante pudo fracasar en el examen; etcétera).

Porque sólo existe certeza -y relación de causalidad- respecto de la pérdida de oportunidades generada, la indemnización se reduce a una estimación del valor de esa chance desaparecida. Usualmente, se expresa ese valor en un porcentaje de oportunidades perdidas, que se multiplicará por el valor total del bien en juego.

\section{LA PÉRDIDA DE UNA OPORTUNIDAD EN LA JURISPRUDENCIA NACIONAL}

En la jurisprudencia nacional la noción parece ser generalmente ignorada, con algunas excepciones recientes. La regla general pareciera que estos daños o bien se califican como conjeturas (daño eventual) o se analizan como lucro cesante imperfecto (con una probabilidad baja de ocurrencia y, por tanto, excluidos de la reparación).

Un ejemplo puede ser ilustrativo del tratamiento clásico: un padre que demandó indemnización por las sumas que su hijo (un joven de 24 años que había egresado con buenos resultados de ingeniería, pero que no percibía rentas aún), le pudo haber aportado de no haber ocurrido el hecho ilícito. En este caso, la Corte de Apelaciones de Concepción, en sentencia de 19 de agosto de 1965, afirmó que si el "accidente ocurre en una persona que, desde el punto de vista económico, podría llamarse improductiva, aquella indemnización no tendría razón de ser”2.

En otros casos la incertidumbre es más patente (o más bien, la probabilidad de acceso al beneficio es más baja). Así, en el caso de un joven y destacado estudiante muerto en un accidente, se demandaron los ingresos que habría recibido trabajando (le faltaban dos años de estudios), tomando en cuenta sus capacidades, relaciones sociales y la esperanza promedio de vida. La Corte de Apelaciones de Santiago rechazó la reparación de ese "lucro cesante", por considerar que se trataban de "meras conjeturas", faltando antecedentes ciertos sobre su capacidad de trabajo y sus posibles actividades futuras ${ }^{3}$.

\footnotetext{
${ }^{2}$ La frase corresponde a una transcripción de la opinión de un autor español, que esta Corte hizo suya. V. Corte de Apelaciones de Concepción, 19 de agosto de 1965, Revista de Derecho de la Universidad de Concepción, 136, pp. 85 y ss.

${ }^{3}$ Corte de Apelaciones de Santiago, 26 de mayo de 1944, Revista de Derecho y Jurisprudencia, t. XLI, p. 41.
} 
Vinculado a lo anterior, como se expondrá, la jurisprudencia chilena ha tendido a rechazar mayoritariamente la indemnización de los ingresos futuros del trabajador muerto a título de lucro cesante.

No obstante, existe un interesante antecedente bastante anterior, una sentencia de 1904, que vale la pena examinar ${ }^{4}$. En este caso, la Corte Suprema confirmó una decisión que concedió indemnización de perjuicios por los recursos que en el futuro habría podido exigir una mujer viuda respecto de su hijo estudiante, quien al momento del accidente, y por sus méritos, había sido admitido a la Escuela Militar (" $4^{\circ}$ Que la demandante con la muerte de su hijo ha sufrido un daño real y efectivo, pues se ve privada, de los recursos que tenia derecho a exigir como madre viuda a su hijo. 5o. Que en autos consta que Ordenes, distinguido alumno de la Escuela de Clases, habia sido llamado, por excepción y atendido sus méritos, a incorporarse a la Escuela Militar") $)^{5}$. La decisión es sumamente escueta y no justifica siquiera a qué título se concede la indemnización (no califica el daño como patrimonial o moral). No obstante, pareciera estimar como un antecedente relevante, como se da cuenta en los considerados transcritos, la probabilidad elevada de que accediera a un empleo remunerado, dados sus méritos y la convocatoria que había recibido para integrar la mencionada Escuela. Tal expectativa se califica de "real y efectiva", utilizando (premonitoriamente) expresiones cercanas a las que se emplean en el presente para denominar las chances cuya pérdida merecen ser reparadas con indemnización (chances "serias" y "reales").

No obstante, una cierta evolución es perceptible en la materia, al menos en los últimos diez años. Y por ello, conviene referirse a los principales grupos de casos abordados por la jurisprudencia nacional reciente:

(i) Accidentes laborales: En hipótesis de accidentes del trabajo, y con independencia de la pensión de invalidez recibida por concepto de seguro obligatorio, la posición tradicional es rechazar la reparación del lucro cesante equivalente a lo que dejará de percibir la víctima hasta el término de la vida laboral. Ello, por cuanto constituirían "meras conjeturas" respecto a la sobrevida de la víctima, así como a la determinación de sus ingresos y a la permanencia en el tiempo de éstos ${ }^{6}$.

El lucro cesante consiste en una ganancia cierta, por cuanto tiene una probabilidad elevada de ocurrencia. Los contratos de trabajo, bien lo sabemos en el despiadado sistema liberal chileno, están sujetos a múltiples (y a veces indignas) contingencias.

Pero, recientemente, varios fallos han cambiado de opinión y han concedido indemnización por un concepto de lucro cesante que en verdad se encuentra

\footnotetext{
${ }^{4}$ Corte Suprema, 25 de octubre de 1904, Revista de Derecho y Jurisprudencia, t. II, pp. 141 y ss.

${ }^{5}$ Considerandos 4 y 5, sentencia de primera instancia, 19 de noviembre de 1903, ibíd., p. 143.

${ }^{6}$ Por ejemplo, por todos, Corte Suprema, 27 de mayo de 2008, LegalPublishing No 39095.
} 
mucho más cercano (en términos de probabilidad de ocurrencia) a la pérdida de una chance.

Así se desprende de los siguientes casos:

Corte Suprema, 13 de junio de 20067: Se confirma una decisión de instancia que otorgó una indemnización, a título de lucro cesante, sobre la base de la siguiente justificación: "Que teniendo presente que el lucro cesante es toda cantidad que el actor hubiera estado percibiendo al momento de la ocurrencia del accidente y que se ha dejado de percibir por motivo del mismo y, considerando los siguientes factores, esto es, que el sueldo, señalando por la parte demandante (fs. 23 vta.) era de \$ 120.000, correspondiente a faena de temporada y ocasional, el cual fue cancelado hasta el mes de junio de 2003, que el organismo asegurador le otorgó una pensión de invalidez del $70 \%$, con vuelta al trabajo $y$, que aún se encuentra en etapa escolar ( $1^{\circ}$ medio al año 2002, con 18 años), según se lee de la demanda de autos, se hará lugar a la misma, en base a una proyección estimativa de dos años más de estudios, esto es entre el año 2005, fecha de término de sus estudios y, a la fecha de cumplir 65 años de edad, en base a diferencia de $\$ 36.000$ mensuales, esto es, 44 años 2 meses, lo que arroja la suma total de \$19.094.000'8.

La simple enunciación de los "factores" que tiene en cuenta esta sentencia son elocuentes acerca de si en verdad estamos hablando de una pérdida de ganancias futuras o, más bien, de una pérdida de posibilidades de obtener ganancias futuras: una proyección de remuneraciones sobre la base de lo obtenido en trabajos ocasionales y temporales; una "proyección estimativa" de los años que le quedaban de estudios; una prolongación de la vida laboral, para los efectos del cálculo, hasta los 65 años, etc. Estos factores son meras hipótesis, con una probabilidad de ocurrencia bastante indeterminada, como se prueba de la circunstancia de que se construyen sobre la base de un trabajo que se reconoce expresamente "temporal" y "esporádico", respecto de una persona que aún no terminaba siquiera la educación media.

Un comentario aparte merece la consideración de la pensión de invalidez que le otorgó el organismo asegurador (pensión de invalidez del 70\%). Sin duda que se encuentra presente la preocupación de no incurrir en una doble indemnización. Más allá, pareciera también que una razón de justicia material, una "razón humanitaria", lleva a la Corte a intentar "completar" la indemnización de esta forma. Y ello porque en numerosos casos, como en esta especie, la indemnización que concede el seguro obligatorio por accidentes del trabajo es inferior a la remuneración que recibía el trabajador. La intención es loable, pero los medios no son los idóneos, pues de esta forma se desdibuja un concepto de lucro cesante de un modo bastante alejado del imperativo de igualdad ante la ley. En efecto, de forma

\footnotetext{
${ }^{7}$ Corte Suprema, 13 de junio de 2006, Rol 4514-2005.

${ }^{8}$ Considerando 19, sentencia de primera instancia, Cuarto Juzgado de Letras de Santiago, 20 de mayo de 2004, Rol 2356-2003.
} 
paralela, la misma Corte exige, en la inmensa mayoría de los casos, la prueba de una probabilidad cercana a la certeza para indemnizar el lucro cesante?

El gran inconveniente de tratar estos daños como lucro cesante, es que se termina rechazando la indemnización (como ocurre en la mayoría de los casos) o aceptándola (como excepcionalmente ocurrió en este caso), y en ambas situaciones se incurre en una abierta injusticia: o bien queda sin reparación alguna la oportunidad perdida (que, ya se ha dicho, tiene un valor económico), o bien se indemniza de forma "completa", como si existiese certeza de que el ilícito provocó el resultado final (cuestión que, como hemos visto, es también injusta). Una consideración adecuada del perjuicio de pérdida de una oportunidad podría constituir un camino más justo para superar estos inconvenientes, tal como se volverá a mencionar más adelante.

Corte de Apelaciones de Santiago, 23 de marzo de $2007^{10}$ : En este caso se trataba de un accidente que ocasiona la muerte de un trabajador minero. La Corte decide indemnizar, a título de lucro cesante, un monto de $\$ 240$ millones, pues estima una expectativa laboral hasta los 55 años (y no hasta los 65 años, "por la naturaleza de la labor realizada por la víctima") ${ }^{11}$, sobre la base de un sueldo promedio de 1,2 millones.

Nuevamente nos encontramos con supuestos hipotéticos (o, incluso, conjeturas), y buena cuenta de ello es la "expectativa" laboral de la víctima que la Corte decide retener, sobre parámetros que ni siquiera menciona.

Corte de Apelaciones de Santiago, 31 de diciembre de 2007 ${ }^{12}$ : En este nuevo caso, la Corte decide otorgar $\$ 10$ millones por concepto de lucro cesante, en atención a lo siguiente: "considerando la edad, remuneración y labores desarrolladas por el actor al momento del accidente -jornalero de la construcción (fuente de sus ingresos)-, corresponde proyectar las consecuencias de la incapacidad que sufriera, por un periodo que resulte coherente con lo normal y previsible. Esta Corte lo fija en 20 años. Por lo tanto, las circunstancias de este caso permiten inferir que, a raiz del accidente, el actor vio disminuidos los beneficios, que, en condiciones de normalidad, obtenía de su trabajo. Así, partiendo de la base que su incapacidad alcanzó un 40\% - medida de la disminución - que su última remuneración ascendió a la suma de $\$ 180.000$ y que, en términos razonables, sus expectativas laborales se han fijado en

\footnotetext{
${ }^{9}$ El zigzagueo judicial en esta materia (como lamentablemente en otras) es simplemente desconsolador. Por ejemplo, se ha fallado que no procede la reparación por concepto de lucro cesante si éste se funda en la imposibilidad de ejecutar trabajos esporádicos, al ser dicha pretensión una mera expectativa de ganancia eventual e incierta, y no una privación de un real beneficio económico producto de las lesiones sufridas (Corte de Apelaciones de Valdivia, 16 de julio 2003, Fallos del Mes No 532, sentencia 11a, p. 691, Gaceta Jurídica No 310, p. 159, y LegalPublishing No 34181).

${ }^{10}$ Corte de Apelaciones de Santiago, 23 de marzo de 2007, Rol 5386-2005.

${ }^{11}$ Considerando $5^{\circ}$.

12 Corte de Apelaciones de Santiago, 31 de diciembre de 2007, Rol 1901-2007, LegalPublishing No 38095.
} 


\section{0 años, se tiene que la pérdida patrimonial experimentada alcanzó la suma total} de $\$ 10.368 .000 "$.

Una vez más nos encontramos que la noción de lucro cesante se extiende a los límites de la reparación de la pérdida de una oportunidad, indemnizando de forma completa el perjuicio sobre la base de especulaciones que tampoco se justifican (¿por qué, en este caso, se consideran 20 años de vida laboral futura?).

Pareciera mucho más pertinente apreciar estos casos de la forma en que lo propuso la Corte de Apelaciones de Concepción, en sentencia de 12 de enero de $2000^{13}$, al afirmar que entre el daño cierto y el daño eventual existe "una zona intermedia, gris, que es la probabilidad suficiente, que es más que la posibilidad pero menos que la certeza, situación que se conoce en el derecho como chance". En tal caso, agrega, debe quedar entregado a la prudencia del juez la determinación del monto de la indemnización. Como se viene exponiendo, tal "prudencia" es la que es posible guiar (a efectos de respetar el principio de igualdad ante la ley) con los criterios de la pérdida de una oportunidad.

En realidad, en varios de estos casos laborales se está indemnizando bajo el rótulo de lucro cesante una pérdida de oportunidad (reparando, entonces, el perjuicio "completo").

(ii) Responsabilidad de abogados: La responsabilidad profesional de los abogados - particularmente, en defensas judiciales- constituye uno de los ámbitos donde es frecuente encontrar, desgraciadamente, hipótesis de pérdida de una oportunidad. Estos casos dicen relación, en esencia, con negligencias profesionales que hacen perder al cliente la oportunidad de ganar el pleito u obtener sentencia absolutoria.

En el derecho nacional, es posible al menos encontrar dos casos en que se fallaron situaciones como éstas, sobre la base de criterios disímiles y con resultados también radicalmente distintos.

Corte Suprema, 11 de abril de $2007^{14}$ : En este caso se trataba un abogado que había sido contratado para defender a un deudor en un juicio interpuesto por una compañía de seguros (que le exigía la restitución de \$26 millones, pagados, en su entender, por error), y por cuya defensa se pactaron honorarios por $\$ 2,6$ millones. La sentencia de primera instancia condenó al deudor a la restitución de la totalidad de esa suma. El abogado del demandado apeló en tiempo y forma, pero no se hizo parte ante el tribunal de alzada, y el recurso fue declarado desierto. La Corte Suprema concedió una suma de 5 millones por concepto de "daño moral" (luego de discurrir sobre la ya superada controversia acerca de su procedencia en materia contractual $)^{15}$.

\footnotetext{
${ }^{13}$ Corte de Apelaciones de Concepción, 12 de enero de 2000, Rol 167-1999.

${ }^{14}$ Corte Suprema, 11 de abril de 2007, Rol 3291-2005, LegalPublishing No 36311.

${ }^{15}$ Efectivamente, pareciera que esta discusión se encuentra superada. V. al respecto: JANA LiTEZKY, Andrés y TAPia Rodríguez, Mauricio (2004). “Daño moral en la responsabilidad contractual. A propósito de un
} 
La hipótesis es un caso perfecto de pérdida de una chance: el abogado, con su negligencia, no se sabe si provocó el resultado final negativo para su cliente (ser condenado a la restitución de los \$26 millones), pero sí es cierto que al menos lo privó de oportunidades de, en segunda instancia, obtener una absolución o una reducción de lo condenado restituir. Más aún, la demandada había también interpuesto una demanda reconvencional de indemnización de perjuicios, cuya suerte también quedó frustrada por la omisión del profesional.

Resulta peculiar la forma en que la Corte determina la naturaleza de este daño, pues sin justificar de qué manera la negligencia del abogado habría afectado a intereses extrapatrimoniales, dedica extensas páginas a justificar cómo el daño moral (que no analiza en la especie) sería procedente, en abstracto, como consecuencia de un incumplimiento contractual. Cabe destacar que la sentencia de primera instancia había acogido la demanda de la actora contra el abogado, condenándolo a pagar el monto total de la suma que la primera debió restituir a la compañía aseguradora $^{16}$. Por su parte, la sentencia de segunda instancia había desestimado la demanda, entendiendo que no existía daño emergente (por cuanto se trataría de la restitución de una suma pagada indebidamente) y que no habría tampoco daño moral (que no sería procedente en materia contractual) ${ }^{17}$.

Los fundamentos del daño moral al que se condenó en este caso deben encontrarse en la sentencia de primera instancia, que hace referencia a la angustia que habría sufrido la víctima producto de esta situación. En tal sentido, no debe extrañar esta solución, pues los contornos del daño moral son objeto en el presente de una extensión bastante discutible y desordenada en la jurisprudencia nacional, y en verdad cualquier afección psíquica se puede plantear como tal ${ }^{18}$. Únicamente se señalará que la invocación del daño moral sirvió en este caso para condenar a una reparación "parcial". Probablemente, la Corte visualizó la injusticia de condenar por el monto total de la deuda, o absolver completamente, cuestión que es el sustrato de la pérdida de una oportunidad.

Un último comentario acerca de la forma de medir la entidad de la oportunidad destruida con el ilícito en este caso. Usualmente, en materia de ejercicio de la abogacía, para determinar la entidad de las chances, es necesario evaluar las probabilidades de éxito estadístico de acciones judiciales o defensa de esa naturaleza. Así, por ejemplo, no es lo mismo alegar como defensa la imputación de incumplimientos recíprocos (cuya existencia e importancia deben probarse y se encuentran sujetos a la apreciación judicial), a alegar la excepción objetiva de que

fallo de la Corte Suprema de 5 de noviembre de 2001”. En: Temas de Responsabilidad Civil, Cuadernos de Análisis Jurídico, Santiago: Ediciones Universidad Diego Portales, pp. 171 y ss.

${ }^{16}$ Segundo Juzgado de Letras de La Serena, 22 de septiembre de 2004, Rol 716-2003.

${ }^{17}$ Corte de Apelaciones de La Serena, 7 de junio de 2005, Rol 1456-2004, LegalPublishing No 36311.

${ }^{18}$ Como el perjuicio psicológico por la pérdida de un vehículo que sirve de fuente de trabajo. Corte de Apelaciones de Antofagasta, 7 de abril de 2008, LegalPublishing No 38694. 
la deuda está prescrita por el transcurso del tiempo. De la misma forma, un análisis estadístico de las demandas acogidas (o rechazadas, según sea el caso) de esa misma naturaleza en esa Corte, puede dar una cuenta de la entidad de la oportunidad destruida con la negligencia del profesional.

Corte Suprema, 27 de octubre de $2008^{19}$ : El caso se fundaba en una defensa laboral por despido injustificado encargada por un trabajador a un abogado de la Corporación de Asistencia Judicial, quien había delegado poder en uno de los postulantes. Producto de la inactividad del abogado y del postulante, se declaró el abandono del procedimiento. Como no se apeló, tal resolución quedó ejecutoriada.

La sentencia de segunda instancia, pronunciada por la Corte de Apelaciones de Valdivia, con fecha 26 de diciembre de $2006,{ }^{20}$ razona expresamente en términos de pérdida de una oportunidad: "Que, en el caso de autos, para determinar si existe un daño, y si dicho daño es cierto; esto es, de que se haya producido realmente como presupuesto indemnizatorio se puede utilizar el expediente acuñado por la doctrina francesa de la perte d'une chance (pérdida de una chance). En otras palabras, la expectativa más o menos cierta de ganar o perder. Ello supone, en el caso de marras, la reconstrucción mental hipotética de lo que habría sucedido si el juicio laboral hubiere sido tramitado completamente"21.

Para tal fin, la Corte realiza un examen muy pertinente, preguntándose acerca de cuál era la entidad de la oportunidad que la acción negligente hizo desaparecer: "Que, asi las cosas, cabe preguntarse, qué probabilidades de obtener, con razonable certeza, de acuerdo con las circunstancias del caso, tenía el actor de autos, demandante también en la causa laboral, si se hubiera ejercido la chance de su total y completa tramitación"'22.

Ahora bien, así como es elogiable la propuesta metodológica de este fallo en torno a la determinación de las chances de que se privó a la víctima, resulta criticable la manera en que pone en práctica esa metodología y los factores que considera para descartar esas oportunidades como objeto de la indemnización de perjuicios. En efecto, la sentencia termina por concluir que las chances, en la especie, no permitirían afirmar la "realidad, efectividad y certidumbre del daño" y que, en consecuencia, se trataría de un daño "hipotético y eventual" excluido de la reparación ${ }^{23}$. Y para llegar a esa conclusión, en orden a que las chances no eran ni reales ni serias, la Corte considera los siguientes dos factores: en primer lugar, la existencia de una excepción de caducidad interpuesta contra la acción laboral,

\footnotetext{
${ }^{19}$ Corte Suprema, 27 de octubre de 2008, Rol 1021-2007.

${ }^{20}$ Corte de Apelaciones de Valdivia, 26 de diciembre de 2006, Rol 1084-2006.

${ }^{21}$ Considerando $5^{\circ}$.

${ }^{22}$ Considerando $6^{\circ}$.

${ }^{23}$ Considerando 6 ${ }^{\circ}$.
} 
que se fundaba, no obstante, en un error cometido en la redacción de la demanda laboral (al señalar una fecha equivocada de término del contrato), "situación en la cual no reparó la propia parte"; y, en segundo lugar, porque que se trataría, "en esencia, del evento incierto de la litis" ${ }^{24}$.

Tales consideraciones parecen por completo discutibles. Ante todo, es efectivo que se había interpuesto una excepción de caducidad contra la acción laboral, producto del error en la redacción de la demanda, pero ello no puede ser imputable, como afirma la sentencia, al "patrocinado". Resulta insólito que se atribuya a un no experto (patrocinado) los efectos de una redacción defectuosa de un escrito judicial que es encargado a un experto (abogado patrocinante y apoderado). Ello equivaldría a sostener, por ejemplo, que un error de diagnóstico en materia médica podría ser atribuible al paciente que no revisó exhaustivamente las conclusiones del médico. En verdad, la consideración de este factor permitía concluir que en la especie ya no se trataba de la discusión de la pérdida de una oportunidad, sino de un daño emergente puro y simple, en conexión causal directa con la negligencia cometida. En otros términos, la negligencia profesional (mala redacción de la demanda) y su consecuencia (la excepción de caducidad interpuesta) no debería evaluarse como un factor que transformara en poco seria la chance, sino más bien como una negligencia profesional que provocaría inevitablemente la pérdida del proceso para el patrocinado.

Por otra parte, el que se trate en estos casos de responsabilidad profesional de la determinación del "evento incierto de la litis", no pasa de ser una constatación evidente, pero que no destruye la seriedad de la oportunidad perdida. En todo caso de pérdida de una chance por negligencias profesionales en el ámbito de una defensa judicial se debe medir el "evento incierto de la litis". Por ello, lo relevante es analizar cuáles eras las posibilidades de éxito de la acción, esto es, las chances que se destruyeron de obtener una sentencia favorable.

La Corte Suprema, sin examinar en detalle la procedencia del análisis de este daño como "pérdida de una oportunidad", confirmó la decisión, porque en su opinión no existiría "un daño cierto y efectivo" 25.

(iii) Pérdida de oportunidades de negocios: La pérdida de oportunidades de negocios también es un ámbito clásico para el análisis en términos de pérdida de una oportunidad.

En el derecho nacional existe al menos un caso relevante reciente, fallado por la Corte Suprema, el 4 de julio de $2011^{26}$. Se trataba de una demanda de responsabilidad contractual interpuesta por un cliente contra su banco. Este último había castigado una deuda, informándola al boletín comercial, pese a estar

${ }^{24}$ Considerando $6^{\circ}$.

${ }^{25}$ Considerando $14^{\circ}$

${ }^{26}$ Corte Suprema, 4 de julio de 2011, Rol 137-2010, LegalPublishing No 49550. 
amparada en un pagaré vencido y pudiendo cargar el monto adeudado a la cuenta corriente (además, el cliente había pagado parte del capital y de los intereses). El demandante alegó, entre otros daños, la pérdida de una oportunidad de efectuar negocios; en concreto, la privación de la oportunidad de ingresar como socio a una sociedad comercial, producto del antecedente comercial negativo informado al boletín comercial. No obstante, en opinión de la Corte, el demandante no habría aportado pruebas suficientes sobre porcentaje social que tenía expectativas de obtener ni acerca de las utilidades a las que podía acceder por esa vía ${ }^{27}$. En síntesis, la sentencia estimó -en términos de pérdida de una oportunidad- que no se acompañaron pruebas concluyentes acerca de la existencia de la chance y sobre su entidad, esto es, cuál era el negocio de que se privó al demandante y cuál era su rentabilidad potencial.

(iv) Responsabilidad médica: Como se dijo, es la medicina la que expone en el presente a un mayor número de daños de esta naturaleza. En ocasiones, es imposible determinar con certeza si la negligencia médica provocó la agravación o la muerte del paciente, pero sí es posible demostrar que tal actuación destruyó sus chances de sanar o sobrevivir. Así ocurre cuando se omite un examen, privando al paciente de la oportunidad de someterse a un tratamiento, o cuando sin ajustarse a la lex artis no se sana una herida, perdiendo el paciente las chances de evitar una invalidez.

En la materia, existe una importante decisión de la Corte de Apelaciones de Valparaíso, de 11 de diciembre de $2008^{28}$, confirmada por la Corte Suprema el 20 de enero de $2011^{29}$, decisión que puede erigirse en un precedente importante en los juicios de responsabilidad civil ${ }^{30}$.

En este juicio se demostró que el médico había cometido un error de diagnóstico (una biopsia realizada con impericia) no detectando un melanoma maligno. Durante un año la paciente no recibió tratamiento adecuado, sufriendo luego fuertes dolores y un aborto espontáneo, que lamentablemente la condujeron a la muerte al año siguiente. La Corte de Apelaciones consideró que no se podía atribuir causalmente la muerte al error de diagnóstico (aparentemente, existía una diseminación previa del tumor y no habían tratamientos efectivos para disminuir la mortalidad de la afección), y por ello no se podía condenar derechamente por la muerte al médico (del paciente y el feto) ${ }^{31}$. Pero, al mismo tiempo,

\footnotetext{
${ }^{27}$ Considerando $15^{\circ}$, sentencia de reemplazo.

${ }^{28}$ Corte de Apelaciones de Valparaíso, 11 de diciembre de 2008, Rol 776-2008.

${ }^{29}$ Corte Suprema, 20 de enero de 2011, Rol 2074-2009. V. un muy breve comentario: Tapia Rodríguez, Mauricio (2011). "Pérdida de una chance". Diario La Tercera, Ideas y debates, 31 de marzo.

${ }^{30}$ El mérito de reparar en la importancia de este precedente debe atribuirse a Ignacio Ríos, ayudante de la Facultad de Derecho de la Universidad de Chile, incansable investigador en esta materia.

${ }^{31}$ Considerando $9^{\circ}$, sentencia de segunda instancia: "no se ha acreditado que entre la muerte de doña Karen Ojeda y la realización de una biopsia en forma negligente exista un nexo causal que permita demandar indemnización por su fallecimiento".
} 
concluyó que el error de diagnóstico le impidió por más de un año acceder a un tratamiento adecuado, mejorar su calidad de vida (disminución del dolor) e incluso prolongarla ${ }^{32}$, cuestión que le generó una "pérdida de chance" a ella y a sus parientes cercanos ${ }^{33}$.

Si bien lamentablemente hay escasa uniformidad en materia de cuantificación del daño en nuestro sistema, en este caso parecen haberse concedido sumas cercanas a una indemnización completa ( $\$ 20$ millones para cada padre y viudo; $\$ 10$ millones para cada uno de sus dos hermanos).

En todo caso, la decisión es destacable. Ante todo, porque en la determinación de la chance perdida toma en cuenta factores que son los esenciales para medir este daño: el carácter irreversible de la enfermedad, la posibilidad de paliar el dolor y la existencia de posibilidades de prolongar la vida. Todas, como se entiende, oportunidades reales y serias. Luego, porque efectivamente en estos casos no existen antecedentes que permitan atribuir el resultado final al error médico, pero sí antecedentes que permiten concluir de manera cierta que tal acción le privó de oportunidades. Quizá lo único que podría cuestionarse (más allá de los montos concedidos) es no haber efectuado un cálculo de las probabilidades de prolongación de vida con un tratamiento oportuno, cuestión que en la ciencia médica es objeto de apreciaciones bastante certeras fundadas en la experiencia en casos similares y los tratamientos disponibles.

Cabe mencionar que la Corte Suprema, al confirmar esta decisión, valida indirectamente el razonamiento de la Corte de Apelaciones de Valparaíso -en materia de pérdida de una chance-, aludiendo a la "pérdida de posibilidades de un mejor tratamiento y una mayor sobrevida de la víctima" 34 .

Por último, debe tenerse presente que existen al menos dos precedentes anteriores, en materia médica, donde la jurisprudencia se había negado a razonar en términos de pérdida de una oportunidad, a diferencia de lo que hizo en este fallo.

En el primero de ellos, fallado por la Corte Suprema, el 18 de julio de 2004, el Servicio de Salud de Concepción había sido condenado en primera instancia (confirmada en apelación) ${ }^{35}$ por las intervenciones quirúrgicas que le causaron la

\footnotetext{
${ }^{32}$ Considerando $11^{\circ}$, sentencia de segunda instancia: "Que en relación a la circunstancia de haberse privado a la paciente tanto de la posibilidad de haber tenido una mejor calidad de vida si hubiera recibido la medicación adecuada para estos casos, durante el tiempo que no supo de su enfermedad, como también de la posibilidad de haber accedido a un tiempo de vida superior al que tuvo...".

${ }^{33}$ Considerando $13^{\circ}$, sentencia de segunda instancia:“...habiéndosele privado también de haber podido aspirar a una sobrevida, aun cuando inexorablemente por la enfermedad que padeció iba a morir, todo lo cual permite concluir que en la especie existió para ella una pérdida de chance". Considerando $14^{\circ}$, sentencia de segunda instancia: "Que no cabe duda que esta pérdida de chance, que constituye el perjuicio sufrido directamente por la víctima también alcanza a sus padres, marido y hermanos".

${ }^{34}$ Considerando $8^{\circ}$.

${ }^{35}$ Corte de Apelaciones de Concepción, 31 de octubre de 2003, Rol 322-2001.
} 
amputación de una mano y del antebrazo a la víctima. En el recurso de casación, el Consejo de Defensa del Estado alegó que no se había acreditado que la negligencia médica hubiese causado la amputación y que se estaba condenando en verdad por "pérdida de oportunidad de un tratamiento diverso" ${ }^{36}$ o por "pérdida de la chance o de la opción" ${ }^{37}$. La Corte Suprema, sin pronunciarse sobre este argumento, estimó que se encontraba suficientemente acreditada la relación causal entre la negligencia y el daño ${ }^{38}$.

El segundo caso se trataba también de una demanda contra el Servicio de Salud de Concepción, quien fue condenado en segunda instancia al pago de una indemnización por la muerte provocada por un error de diagnóstico (no detección oportuna de una hemorragia cerebral) ${ }^{39}$. En el recurso de casación en el fondo, nuevamente el Servicio de Salud de Concepción argumentó que se le estaría "condenando por un daño no contemplado en nuestro ordenamiento jurídico, como lo es lo que la doctrina ha denominado la pérdida de la chance" ${ }^{40}$. La Corte Suprema, el 23 de junio de $2009^{41}$, revocó el fallo, por considerar que no existiría relación causal entre la negligencia en el diagnóstico y el resultado fatal, "ya que dada la naturaleza de la enfermedad de todas formas existía la posibilidad de que falleciera" ${ }^{42}$. En definitiva, a diferencia del caso anterior, en éste la Corte estimó que no había causalidad respecto al resultado final, pero igualmente sin detenerse a analizar la pérdida de oportunidades de sobrevivir (prolongar la vida) de que se había privado a la víctima ${ }^{43}$.

Como es evidente, el fallo mencionado de 20 de enero de 2011, representa una clara evolución respecto de estos casos, pues asume directamente la discusión de la pérdida de una oportunidad de sanar o sobrevivir en el caso de la responsabilidad médica.

En síntesis, de lo expuesto puede concluirse que la pérdida de una oportunidad constituye un perjuicio que implícita o explícitamente está siendo reconocido en nuestro derecho, por la jurisprudencia descrita.

\footnotetext{
${ }^{36}$ Considerando $7^{\circ}$, Corte Suprema.

${ }^{37}$ Considerando $12^{\circ}$, Corte Suprema.

${ }^{38}$ Considerandos $16^{\circ}$ y $18^{\circ}$, Corte Suprema.

${ }^{39}$ Corte de Apelaciones de Concepción, 23 de septiembre de 2006, Rol 3530-2004.

${ }^{40}$ Considerando $3^{\circ}$, Corte Suprema.

${ }^{41}$ Corte Suprema, 23 de junio de 2009, Rol 6274-2007.

${ }^{42}$ Considerando $5^{\circ}$, Corte Suprema.

${ }^{43}$ A estos casos debería agregarse un tercero (también reciente) en el que la víctima argumentó en términos de pérdida de una chance. Se trataba de un jugador de futbol que sufrió una lesión en un entrenamiento, que no habría sido debidamente diagnosticada y tratada, y que demandó la reparación de la pérdida de una chance por la privación de acceder a una carrera futbolística. No obstante, se estimó que no se había configurado el ilícito por parte del demandado, no entrando en la discusión acerca de la procedencia de este daño. V. Corte Suprema, 28 de octubre de 2010, Rol 7147, LegalPublishing No 46893.
} 
La pregunta es si debe o no avanzarse hacia un reconocimiento más explícito, que se haga cargo de los elementos que configuran este daño y de las formas de cálculo de su indemnización (la avaluación del daño como el costo de la oportunidad y no en relación al resultado final). Dadas las desigualdades que enfrenta su tratamiento jurisprudencial actual, inorgánico y desarticulado, pareciera que existen razones de justicia que así lo justificarían. 